\title{
PROFIL KEMAMPUAN KOGNITIF SISWA SMA DALAM PEMBELAJARAN FISIKA MENGGUNAKAN TEKNIK PEMBELAJARAN 'TAKE-AWAY'
}

\author{
Ria Trisnia Naufalina ${ }^{1 *}$, Irma Rahma Suwarma ${ }^{2}$, Asep Sutiadi ${ }^{3}$ \\ ${ }^{1}$ Pendidikan Fisika FPMIPA UPI, Jl. Dr. Setiabudhi No.229, Bandung, 40154 \\ *Email : riatrisnianaufalina@gmail.com
}

\begin{abstract}
ABSTRAK
"Take-away" merupakan suatu teknik pembelajaran yang bertujuan untuk mengembangkan sikap dan kemampuan pengambilan intisari dari pembelajaran yang telah dilakukan oleh peserta didik. Dengan diterapkannya teknik takeaway ini diharapkan akan muncul rasa tanggung jawab siswa untuk melakukan pembelajaran mandiri, baik sebelum dan setelah pembelajaran yang dilakukan di sekolah. Tujuan dari penelitian ini adalah untuk mengetahui bagaimana profil kemampuan kognitif siswa sebelum dan sesudah diterapkannya teknik pembelajaran "Take-Away". Metode penelitian yang digunakan adalah Pre-Experimental dengan desain One-Group Pretest-Posttest. Penelitian ini melibatkan siswa SMA kelas XI di salah satu SMA di kota Tasikmalaya yang berjumlah 33 orang. Instrumen penelitian berupa tes yang dapat mengukur kemampuan kognitif siswa pada ranah C2 (memahami), C3 (mengaplikasi) dan C4 (menganalisis), soal essay, dan rubrik penilaian. Data di olah menggunakan analisis deskriptif persentase. Hasil dari penelitian ini menunjukkan bahwa kemampuan kognitif siswa sebelum diterapkannya teknik pembelajaran "Take-Away" masih rendah, hanya 9\% siswa yang mendapatkan nilai diatas nilai KKM (Kriteria Ketuntasan Minimal), sedangkan setelah diterapkannya teknik pembelajaran "Take-Away” kemampuan kognitif siswa mengalami peningkatan dengan 63\% siswa mendapatkan nilai diatas nilai KKM (Kriteria Ketuntasan Minimal). Dengan demikian, terdapat perbedaan profil kemampuan kognitif siswa sebelum dan sesudah diterapkannya teknik pembelajaran "Take-Away".
\end{abstract}

Kata Kunci : Teknik pembelajaran “Take-Away”, kemampuan kognitif, kemampuan pengambilan intisari, tanggung jawab, pembelajaran mandiri

\begin{abstract}
The title of this research is "Profile of Cognitive Abilities on students' High School in Learning Physics with TakeAway Technique". The purpose of the Take-Away Techniqueis to develop the students' attitude and ability for taking the core of learning. The use of the Take-Away Technique expected to appear the sense of responsibility of students to conduct independent learning either before or after learned in school. The purpose of this study was to determine how the profile of cognitive abilities on students' High School before and after using the Take-Away Technique. The research used Pre-Experimental methode and One-group pretest-posttest design. The Take-Away Technique applied in one of high school in Tasikmalaya city with 33 students. The research instrument is a test to measure students' cognitive abilities in the sphere of C2 (understand), C3 (apply) and C4 (analyze), essay test and assesment rubric. The results of this study indicate that students 'cognitive abilities before applying the Take-Away Technique are still low, only $9 \%$ of students who received grades above KKM (minimal completeness criteria), while after applying the Take-Away Technique student's cognitive abilities increased by $63 \%$ of students who received grades above KKM (minimial completness criteria). Therefore, there are differences in the profile of students' cognitive abilities before and after applied the Take-Awat Technique.
\end{abstract}

Keywords: "Take-Away" Technique, cognitive ability, ability for taking the core of learning, responsibility, independent learning 


\section{Pendahuluan}

Untuk mengetahui bagaimana hasil belajar siswa, peneliti melakukan studi pendahuluan ke salah satu sekolah di kota Tasikmalaya. Peneliti menganalisis nilai ulangan harian siswa untuk mengetahui bagaimana hasil belajar siswa. Setelah menganalisis hasil belajar siswa, ternyata terdapat suatu masalah dimana nilai rata-rata ulangan harian pelajaran fisika paling rendah diantara pelajaran yang lainnya. Untuk mengetahui apa penyebab dari masalah tersebut, peneliti melakukan wawancara kepada guru mata pelajaran fisika untuk mengetahui bagaimana proses pembelajaran fisika dan sikap siswa pada saat proses pembelajaran berlangsung. Hasil dari wawancara, ditemukan bahwa :

1. Guru selalu memberikan soal-soal hitungan daripada konsep kepada siswa sehingga kemampuan pemahaman konsep siswa masih rendah.

2. Guru merasa kesulitan dalam meningkatkan motivasi siswa untuk belajar fisika.

3. Siswa kurang antusias ketika proses pembelajaran fisika.

4. Guru jarang melakukan evaluasi di akhir pembelajaran pada setiap pertemuannya.

5. Guru jarang memberikan tugas resume kepada siswa.

Selain wawancara kepada guru mata pelajaran fisika, peneliti menyebarkan angket kepada siswa untuk mengetahui permasalahan yang dirasakan oleh siswa. Setelah menganalisis jawaban angket yang diberikan siswa, terdapat beberapa permasalahan yang dirasakan siswa pada saat proses pembelajaran fisika, yaitu :

1. Siswa merasa terbantu dengan pelaksanaan tahap evaluasi yang ada pada kegiatan penutup.

Bentuk pernyataan :

- Saya merasa terbantu untuk mengambil inti pembelajaran yang telah dilakukan dengan pemberian soal di akhir pembelajaran.

- Pemberian soal di akhir pembelajaran membuat saya mengingat-ingat kembali materi yang telah di pelajari.

- Dengan adanya diskusi dan pengambilan intisari yang dilakukan di akhir pembelajaran membuat saya mengingat materi yang sudah dipelajari.

2. Kepedulian siswa terhadap tugas rumah yang diberikan guru

Bentuk pernyataan :

- Pemberian tugas berupa resume meningkatkan ingatan saya mengenai materi yang telah dipelajari.

- Saya selalu berusaha menyelesaikan tugas fisika dengan tepat waktu.

- Dengan guru mengkoreksi tugas resume yang saya buat membuat saya mengetahui cara penulisan yang baik dan benar.
Setelah menganalisis hasil angket yang diberikan kepada siswa, ternyata siswa merasa tidak peduli dengan perolehan nilai fisika, hal ini menunjukkan bahwa motivasi siswa untuk melakukan pembelajaran fisika masih rendah. Permasalahan ini diperkuat dengan data wawancara yang menyebutkan bahwa guru merasa kesulitan untuk meningkatkan motivasi belajar siswa. Dan setelah menganalisis data hasil wawancara, kemungkinan penyebab dari permasalahan ini adalah metode pembelajaran yang digunakan oleh guru yaitu metode pembelajaran ceramah kurang tepat. Penggunaan metode ceramah membuat tingkat ketertarikan dan motivasi siswa untuk mempelajari pelajaran fisika masih rendah. Kurangnya tingkat ketertarikan siswa dalam mempelajari pelajaran fisika ini menyebabkan siswa kurang aktif pada saat proses pembelajaran berlangsung. Kemampuan pemahaman konsep siswa yang masih rendah mengakibatkan kurangnya rasa ingin tahu terhadap fenomena seharihari yang berkaitan dengan konsep fisika. Kurangnya rasa ingin tahu siswa menyebabkan keterampilan bertanya siswa masih rendah. Oleh karena itu, dibutuhkan suatu metode pembelajaran yang dapat meningkatkan rasa ingin tahu siswa sehingga siswa termotivasi untuk terlibat dalam pembelajaran fisika secara aktif. Guru dapat mengarahkan perhatian siswa, agar khusus memperhatikan unsur-unsur pokok dalam materi pelajaran. Hal ini dapat diusahakan dengan menunjukkan kejadian tertentu dalam suatu demonstrasi (Abdul Majid, 2011, hlm. 103).

Dari hasil penyebaran angket pun di dapatkan bahwa siswa merasa terbantu dengan dilaksanakannya evaluasi di akhir pembelajaran dan pemberian tugas berupa resume, namun dari hasil wawancara, guru jarang memberikan evaluasi di akhir pembelajaran pada setiap pertemuannya. Sehingga dibutuhkan suatu tindakan yang dilakukan di akhir pembelajaran selesai untuk meningkatkan kemampuan siswa dalam mengingat materi dan mengambil intisari dari pembelajaran yang telah dilakukan dan penugasan untuk meningkatkan daya ingat siswa terhadap materi yang telah di sampaikan. Berdasarkan teori kognitif (Ashcraft, 2001; dan Schungk, 2011), sangat penting melakukan proses pembelajaran di akhir, proses pembelajaran ini dapat dilakukan melalui komunikasi dan penugasan yang dapat membantu siswa saling bertukar konsep yang di dapat selama pembelajaran dan dapat membuat siswa mengingat materi dalam jangka waktu yang lama.

Terkait dengan alternatif solusi masalah pembelajaran tersebut, Carfio (2010, hlm. 269) telah mengembangkan suatu teknik pembelajaran yang berfokus pada aktivitas siswa pada saat proses pembelajaran. Teknik pembelajaran ini dirancang agar selama proses pembelajaran siswa mampu berfikir aktif yang dapat meningkatkan daya ingat mengenai pembelajaran yang telah disampaikan. Carfio menyatakan bahwa teknik pembelajaran "Take-away" 
ini tidak bisa berdiri sendiri, harus dipadukan dengan model atau metode pembelajaran. Selain itu, di dalam jurnalnya Carfio menyatakan bahwa "Take-away" ini cocok diterapkan pada siswa yang memiliki kemampuan menengah ke bawah. Berdasarkan penelitian yang dilakukannya tentang penggunaan teknik "Take-away" pada pembelajaran fisika di sekolah menengah atas, ternyata teknik "Take-away" ini mempengaruhi hasil belajar siswa. Beberapa hasil dari penelitian ini menunjukkan bahwa adanya peningkatan pada hasil belajar siswa dan kemampuan siswa dalam mengambil intisari setelah pembelajaran. Selain itu dengan diterpakannya teknik pembelajaran "Take-away", kemampuan daya ingat siswa meningkat. Hasil penelitian lain yang mendukung adalah penelitian dari Elderana (2014) yang dilakukan di salah satu SMA di Kota Bandung pada materi Mekanika Newton. Hasil penelitiannya menyatakan bahwa penggunaan teknik pembelajaran "Take-away" di akhir pembelajaran fisika dapat meningkatkan hasil belajar siswa pada ranah kognitif.

Dari pemaparan tersebut, peneliti teratarik untuk melakukan uji coba penggunaan teknik pembelajaran "Take-away" pada siswa SMA kelas sebelas di salah satu sekolah di Kota Tasikmalaya yang memiliki kemampuan awal pada tingkat rata-rata dalam materi Momentum dan Impuls dengan menggunakan metode pembelajaran demonstrasi yang di padukan dengan teknik pembelajaran "Take-away". Hasil belajar yang akan di analisis oleh peneliti adalah hasil belajar pada ranah kognitif, ranah afektif dan ranah psikomotor.

Oleh karena itu, peneliti mengambil judul penelitian "Analisis Hasil Belajar Siswa SMA pada Materi Momentum dan Impuls dengan Menggunakan Metode Pembelajaran Demonstrasi Yang Di Padukan Dengan Teknik Pembelajaran "Take-Away".

\section{Metode Penelitian}

\section{A. Desain Penelitian}

Desain penelitian yang digunakan adalah metode penelitian eksperimen, yaitu metode penelitian yang dilakukan untuk mempengaruhi pengaruh treatment pada kondisi yang di teliti (Wiersma dan G.Jurs, 2009, hlm. 64). Jenis maetode penelitian yang digunakan adalah jenis Pre-Experimental dengan desain One-Group Pretest-Posttest. Desain penelitian ini menggunakan satu kelompok. Kelompok yang dijadikan sampel tersebut sesuai dengan kondisi semula (tidak dilakukan rendomisasi). Kelompok tersebut diberi pretest sebelum dilakukan perlakuan. Perlakuan disini berupa penerapan teknik pembelajaran "Take-away" yang dilakukan di akhir pembelajaran pada setiap pertemuannya. Setelah seluruh pertemuan untuk materi momentum dan impuls selesai, dilakukan posttest. Desain penelitian yang digunakan adalah One-Group Pretest-Posttes dengan satu kelas yang diberikan treatment atau perlakuan, diawali dengan pretest dan di akhiri dengan posttest. (Sugiyono, 2015, hlm. 111)

\section{B. Populasi dan Sampel}

Populasi dalam penelitian ini adalah siswa kelas XI di salah satu SMA di Kota Tasikmalaya. Penentuan sampel dalam peneletian ini melakukan teknik sampling Purposive. Dalam teknik sampling Purposive ini sampel tidak dipilih secara acak namun dipilih sesuai pertimbangan tertentu yang didasarkan atas ciri-ciri tertentu. (Margono, 2010, hlm. 128). Peneliti menentukan sampel dengan melihat hasil belajar siswa, dimana yang dijadikan sampel adalah kelas dengan siswa yang memiliki hasil belajar paling rendah. Alasan penggunaan teknik ini karena karakteristik dari teknik "Take-away" yaitu diterapkan pada siswa yang memiliki kemampuan menengah ke bawah.

\section{Instrumen Penelitian}

Instrumen yang digunakan pada penelitian ini adalah sebagai berikut:

1. Soal pilihan ganda ini berisi soal yang berhubungan dengan materi Momentum dan Impuls. Soal-soal yang dibuat terdiri dari ranah C2 sampai C4. Kegunaan pemberian instrumen ini adalah untuk mengetahui kemampuan kognitif siswa sebelum dan sesudah pembelajaran dengan menggunakan teknik pembelajaran "takeaway”. Instrumen ini diberikan kepada siswa saat pretest dan posttest.

2. Soal essai yang dibuat berbentuk uraian nonobjektif. Bentuk soal uraian non-objektif menuntut siswa untuk mengingat dan mengorganisir gagasan-gagasan pribadi atau hal-hal yang telah dipelajarinya dengan cara mengemukakannya dalam bentuk uraian tertulis (Arifin, 2009, hlm. 127). Butir soal yang dibuat adalah soal yang dapat mengarahkan siswa untuk mengetahui intisari dari pembelajaran yang telah dilakukan.

3. Rubrik yang digunakan adalah rubrik penilaian teknik pembelajaran "TakeAway" tahap satu dan dua yang diambil dari jurnal 'Increase Undergraduate Studens' Higher Order Learning And Course Achievement Throuht The Take Away Technique'.

\section{Hasil dan Pembahasan}

Penelitian dilaksanakan di satu kelas dimana kelas tersebut diterapkan treatment teknik 
pembelajaran "Take-away" dengan empat kali pertemuan. Kelas yang di jadikan objek penelitian adalah kelas yang memiliki nilai fisika paling rendah di antara kelas lainnya yang mendapatkan pengajaran yang sama. Pada kelas ini diterapkan teknik pembelajaran "Take-Away".

Pada pertemuan pertama, siswa diberikan tes awal (pretest) untuk mengetahui bagaimana kemampuan kognitif awal. Pada pertemuan keempat, siswa diberikan tes akhir (posttest) untuk mengetahui bagaimanan kemampuan kognitif siswa setelah treatment diterapkan.

Hasil pengolahan pretest dan posttes didapatkan bahwa sebelum dilakukan treatment siswa yang memiliki nilai diatas KKM $(\mathrm{KKM}=75)$ hanya $9 \%$ yaitu sejumlah 3 orang. Sedangkan setelah treatment dilakukan siswa yang memiliki nilai diatas KKM meningkat menjadi $63 \%$ yaitu sejemulah 21 orang. Perbedaan kemampuan kognitif sebelum dan sesudah diterapkan teknik pembelajaran "TakeAway" dapat dilihat pada setiap ranah melalui bagan dibawah ini.

Bagan 1. Jumlah jawaban benar pada saat pretest dan posttest pada ranah kognitif C2

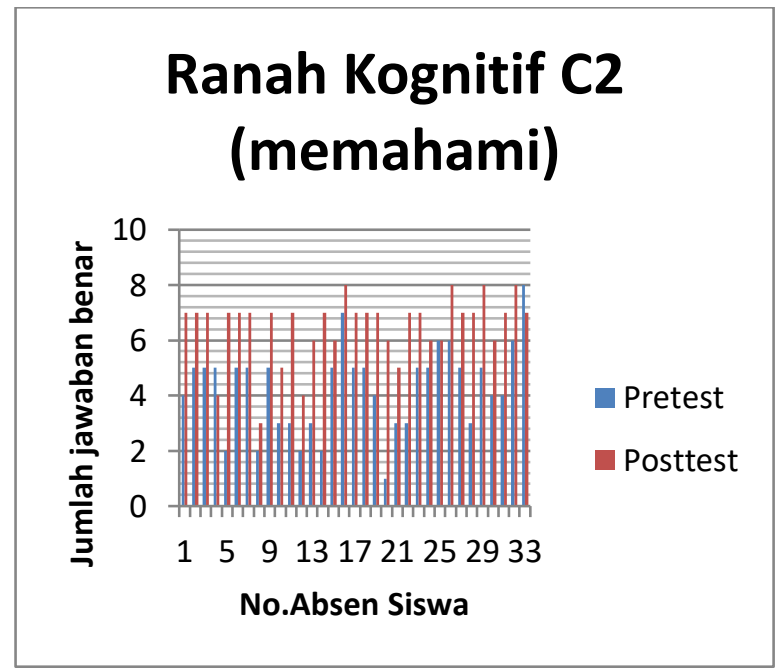

Bagan 2. Jumlah jawaban benar pada saat pretest dan posttest pada ranah kognitif C3

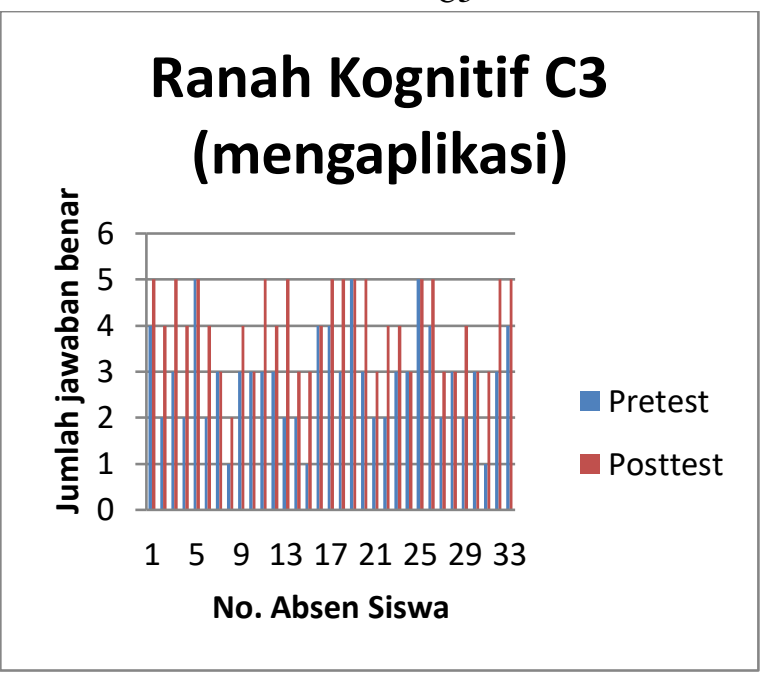

Bagan 3. Jumlah jawaban benar pada saat pretest dan posttest pada ranah kognitif C4

\section{Ranah Kognitif C4 (menganalisis)}

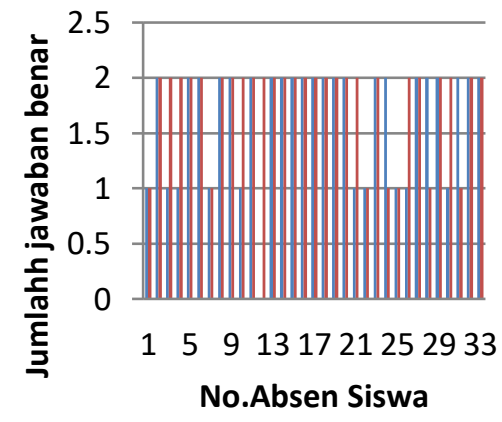

Pretest

Posttest

Keterangan :

Jumlah soal : 15 soal

Jumlah soal ranah C2: 8 soal

Jumlah soal ranah C3: 5 soal

Jumlah soal ranah C4 : 2 soal

Kenaikan kemampuan kognitif siswa ini sesuai dengan kenaikan rata-rata nilai "Take-away" untuk setiap pertemuannya. Kenaikan rata-rata nilai "Takeaway" ini dapat di lihat melalui grafik di bawah ini. 
Grafik 1. Nilai Rata-rata 'Take-away' untuk setiap pertemuan

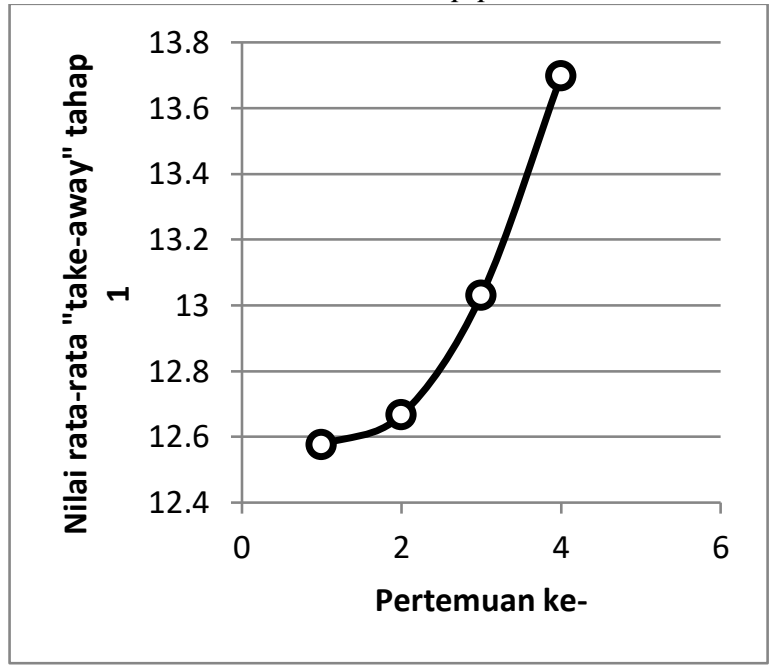

\section{Simpulan}

Berdasarkan data hasil dan pembahasan di dapatkan bahwa terdapat perbedaan antara profil kemampuan kognitif siswa sebelum dan setelah diterapkan teknik pembelajaran "Take-Away”.

\section{Daftar Acuan}

[1] Carifio, James, Lisa Erikson dan Shanna Thompson. (2013). 'Increase Undergraduate Studens' Higher Order Learning And Course Achievement Throuht The Take Away Technique'. University of MassachusettsLowell. Internasional Research Journals vol. 4 (8) pp. 574-606.

[2] Carifio, James \& Michael Doherty. (2012). 'Result of Using the Take away Technique on' Students' Achievements and Attitudes in High School and Physics Science Courses'. Lowell, USA : Canadian Center of Science Education Publisher.

[3] Carifio, James (2013). 'The TakeAwayTechnique for Increasing Higher Order Learning and Achievenment'. University of Massachusetts-Lowell, USA. International Journal of Humanities and Social Science vol.3 n0. 16.
[4] Meritt et al, (2007). 'Middle School Students' Development of the Particle Model of Matter'. A paper presented at the annual meeting of the National Association of Research in Science Teaching, April 2007, New Orleans, LA.

[5] Arifin, Z.(2009). Evaluasi Pembelajaran. Bandung : Remaja Rosdakarya.

[6] Margono, S. (2010). Metodologi Penelitian Pendidikan. Jakarta : Asdi Mahasatya.

[7] Sugiyono. (2015). Metode Penelitian Pendidikan. Bandung : ALFABETA. 
